\title{
СИМУЛЯЦИОННЫЕ ДЕЛОВЫЕ ИГРЫ В УЧЕБНОМ ПРОЦЕССЕ ВЫСШЕЙ ШКОЛЫ
}

\section{SIMULATION BUSINESS GAMES IN THE EDUCATIONAL PROCESS OF HIGHER SCHOOL}

\section{Dyuzheva \\ N. Rogovskaya}

Summary: The simulation game is one of the types of business games. Unlike business games, it is as close as possible to the real conditions of the organization's functioning, its individual business processes, management subsystems. The article discusses the requirements that must be met when organizing a simulation business game; its stages are indicated; the advantages and disadvantages are identified.

Keywords: simulation, simulation business game, participants of the business game, requirements for organizing and conducting a simulation business game, stages of implementation of a simulation business game.
$\mathrm{B}$ условиях цифровизации образования симуляция становится современной технологией обучения в высшей школе. Симуляция способна не только эмоционально вовлечь обучающихся в учебный процесс, но и сформировать у них компетенции, необходимые для будущей профессиональной деятельности. В процессе симуляционного обучения нарабатываются умения выполнения повседневных стандартных операций и действий, а также практические навыки; накапливается и личный опыт решения управленческих задач.

Актуальность заявленной темы состоит в том, что симуляционная игра, максимально приближенная к реальным условиям функционирования организации, позволяет участникам получать необходимый практический опыт при решении профессиональных проблем. В ходе игры у обучающихся формируются общие и профессиональные компетенции, представленные в образовательном стандарте и необходимые в дальнейшем для выполнения должностных обязанностей в соответствии с должностью. Игра способствует формированию устойчивости мыслительного процесса, развитию профессиональной памяти в процессе обучения. Когда становится ясно, что для реализации поставленной цели недостаточно имеющихся теоретических знаний, практических умений, студенты начинают самостоятельно вырабатывать навык поиска иных способов ее разрешения. В подобной ситуации большинство участников приобретают самое главное и ценное - новый опыт, построенный на основе проб, достижений и ошибок.
Дюжева Марина Борисовна

К.э.н., дочент, Омский государственный университет путей сообщения

Dyzgeva@mail.ru

Роговская Наталья Ивановна

К.ф.н., дочент, Омский государственный университет путей сообщения rogovskaya_ni@mail.ru

Аннотация: Симуляционная игра является одной из разновидностей деловых игр. В отличие от деловых игр она максимально приближена к реальным условиям функционирования организации, ее отдельным бизнес-процессам, подсистемам управления. В статье рассматриваются требования, которые необходимо соблюдать при организации симуляционной деловой игры; обозначены ее этапы проведения; определены преимущества и недостатки.

Ключевые слова: симуляция, симуляционная деловая игра, участники деловой игры, требования к организации и проведению симуляционной деловой игры, этапы реализации симуляционной деловой игры.

С древнейших времен и по настоящее время игра остается одной из значимых технологий обучения людей. Известно, что в эпоху античности будущие цари и фараоны обучались секретам управления государством на их основе. В те годы игра была важнейшим способом передачи накопленного опыта от старшего поколения к младшему. Подражая взрослым, наследники престола при изучении проблемы находили свои пути ее разрешения, тем самым формировали где-то уникальный и неповторимый подход к управлению различными сферами деятельности государства [4, с. 71].

Первые деловые игры создавались исключительно для обучения офицеров правилам ведения боя (XVII XVIII вв.). Военные действия разворачивались на шахматной доске имитирующей поле сражения, где король представлял крепость, ферзь - пехоту и т.д., а правила ведения игры описывались математическими формулами.

С 1798 г. возможные комбинации военных действий стали фиксировать на географической карте. К примеру, Наполеон проигрывал свои будущие сражения, используя булавки с разноцветными головками для обозначения мест размещения и передвижения военных частей французской армии и ее противников.

Что касается России, то подобные учебные военные игры впервые стал применять Петр I, тому способствовало его увлеченность западными идеями управления 
государством. Русский царь организовал «потешное войско» и проводил с ним военные учения, прививая его участникам необходимые навыки ведения боевых операций, правила поведения на войне $[5 ; 6]$.

В области управления первая деловая игра - «Перестройка производства в связи с резким изменением производственной программы» - была проведена в 1932 года. Ее автором стала преподаватель Ленинградского инженерно-экономического института - М.М. Бирштейн. Цель игры заключалась в отработке процесса запуска нового цеха. В период индустриализации производства в советской России сложилась такая ситуация, при которой заводы своевременно оснащались оборудованием, обеспечивались необходимых количеством специалистов, но их запуск затягивался и, соответственно, производственный план не выполнялся в полном объеме. Мария Мироновна Бирштейн выявила проблему запуска, связав ее с отсутствием личного опыта разворачивания масштабного производства у руководителей. Она первая выдвинула идею обучения руководителей по подобию обучения военных. Успех игры был определен. Стало очевидно, что решения, принятые в игровой форме, экономически эффективны и целесообразны, могут быть применены на практике.

В последующие годы на основе деловой игры М.М. Бирштейн было разработано и проведено более 40 деловых игр по различным направлениям управления предприятием. К примеру, результатом их применения стало внедрение диспетчерской службы в производство. Диспетчерами назначались специалисты, не имевшие опыта подобной работы. Для их вхождения в должность, получения представления о профессии, создания первичного опыта работы, проводились «диспетчерские» игры.

Однако с 1938 г. деловые игры в управлении оказались под запретом. Альтернативные варианты решения производственных и иных проблем организации, не всегда вписывались в принятую идеологию и расходились с единственным правильным курсом политической элиты. Помимо того, в конце 1930-х - до середины 1940-х гг. страна переживала тяжелые военные времена; игры были не уместны [2].

Возрождение деловых игр в России приходится на 1950-е гг., когда под руководством Г.П. Щедровицкого был создан Московский методологический кружок. Его подход к решению вопросов управления вписывался в идеологию советского общества. В игре решались не задачи участника игры, а государства в целом, учитывались интересы последнего, поскольку государство являлось главным заказчиком, источником финансирования предприятия.

В 1966 г. была проведена игра «Реформа», в 1968 г. -
«Астра», созданные профессором Ленинградского финансово-экономического института И.М. Сыроежкиным. В эти же года начинают функционировать научные центры в Москве, Санкт-Петербурге, Новосибирске и других городах страны, которые стали заниматься и разработкой деловых игр.

В 1975 г. под руководством Центрального экономического института АН СССР и Московского государственного университета, в частности его экономического факультета, в г. Звенигороде открывается школа «Деловые игры и их программное обеспечение». До этого времени школ, специализирующихся только на разработке игр, не было. Звенигородская школа «взрастила» и подарила мировому сообществу ученых известных теоретиков и практиков в области деловых игр: Ю.С. Арутюна, А.А. Вербицкого, Б.Н. Герасимова, Ц.Ф. Комарова, А.Л. Лифшица и многих др.

В дальнейшие годы подобные школы создаются в Таллине (школа В.К. Тарасова), Ленинграде (эмоционально-игровая методика Е.В. Гильбо) [2].

Общая особенность деловых игр, разработанных во второй половине XX века, заключалась в том, что они в первую очередь затрагивали производственные проблемы управления советских предприятий.

С середины 1980-х гг. стали разрабатываться имитационные (симуляционные) игры, затрагивающие не только экономические аспекты управления, но и медицинские, архитектурные, культурологические, экологические и другие направления. К примеру, в сфере экономики была проведена игра «Введение арендного подряда на пивоваренном заводе Омска», политики «Выборы руководителя на ВАЗе», экологии - «Сохранения экологии озера Байкал» [5].

В 1990-е гг. из-за отсутствия финансирования многие работы ученых по разработке деловых игр и их внедрению в практику управления были приостановлены или прекратились вовсе. Вместе с тем, в эти годы начинается массовое внедрение персональных компьютеров, что способствовало развитию компьютерных игр, в том числе и в сфере управления. Так, в 1997 г. группа белорусских специалистов при поддержке немецкого фонда Х. Никсдорфа создала деловую игру «Никедорф Дельта». Эта игра актуальна и своевременна по сей день, в нее охотно играют студенты ОмГУПС в рамках дисциплин экономического профиля. В основе компьютерной игры лежит имитационная модель предприятия, функционирующего в условиях рыночной конкуренции.

В настоящее время выделяют такие направления в развитии игр, как: деловые игры (настольные, к примеру, «Монополия», «Антимонополия» и др. или в «гибридном» 
состоянии); компьютерные симуляторы, наподобие раннее упомянутой игры «Никедорф Дельта»; On-line симуляции и конструкторы деловых игр; геймификация образования, когда обучающийся полностью погружается в мир игры или когда в процессе обучения используются отдельные ее элементы.

Профессиональные и бизнес-тренинги в сфере управления персоналом, производством, организацией в целом базируются на симуляционных деловых играх, а в последнее время еще и на основе цифровизации.

Отметим, что авторы статьи активно применяют в учебном процессе игровые прогрессивные технологии обучения. Опыт показывает, что студенты являются безграничным источником уникальных идей, которые можно и нужно воплощать в жизнь. Часть идей, разработанные в рамках теоретического изучения дисциплин «Менеджмент», «Управленческие решения», «Игровые технологии в коммерции» получили свою реализацию в практической жизни общества. К примеру, карты при оплате проезда в общественном транспорте и маршрутном такси; букеты из памперсов для новоиспеченных родителей; развивающие центры и игровые комнаты для детей; теплые остановки стали привычными и обыденными для жителей города Омска. Однако при разработке и обосновании этих идей на учебном занятии не всегда они воспринимались серьезно и зачастую вызывали смех и критику у самих обучающихся.

Успешный бизнесмен А.Г. Платонов на протяжение многих лет активно сотрудничал с Омским университетом путей сообщения, предоставляя места практик, в дальнейшем - рабочие места выпускникам кафедры «Менеджмент, маркетинг и коммерция». На одной из открытых встреч студентами в игровой форме была предложена идея названия салонов связи «Изюм», и как фирменный знак - изюм в блистере при покупке смартфона, телефона, планшета или какого-либо аксессуара. В дальнейшем эта идея была проработана специалистами компании и положена в основу ее ребрендинга.

В преподавании экономических дисциплин в большей степени используются симуляционные деловые игры. Симуляционная игра является разновидностью деловой игры. Это специально созданная игровая модель, максимально приближенная к реальным условиям работы конкретной компании. Она позволяет ее участникам отработать навыки управления в импровизированных условиях.

При проведении симуляционной деловой игры необходимо руководствоваться определенными требованиями $[4$, с. $72-73]$.

Первая группа из них носит методический характер.
Так, игра должна быть логически связана с темой учебной дисциплины, быть ее продолжением, дополнением или завершением; четко прописываться в рабочей программе и календарном плане. Для ее проведения необходимо подготовить учебно-методическую документацию, в которой проработать задачи, условия, правила, порядок проведения и оценки результатов игры, определить временные границы на каждый из ее этапов.

Определенные требования предъявляются модератору игры, в данном случае педагогу. Именно от него зависит то, насколько грамотно, точно подобран материал; отображает ли он суть поставленной проблемы в управлении организацией; актуален и своевременен; приближен к современным реалиям бизнеса; доступен для понимания студентов, способен вызвать интерес у них; вовлечь обучающихся в игровой процесс.

Регулярная работа с аудиторией позволяет преподавателю учесть состав группы, уровень сплоченности и конфликтности в ней; выявить индивидуальные особенности студентов, их готовность и желание участвовать в симуляционной игре. В одной студенческой группе игра может захватить всех участников, проходить эмоционально с отстаиванием и обоснованием наработанных решений в дискуссии. В другой группе на первых минутах ее проведения становится ясно, что игра не вызвала интерес у обучающихся. Для профилактики и предотвращения второго варианта группового поведения студентов в игре, педагогу-модератору необходимо дополнительно, на этапе ее подготовки поработать с группой, в открытом диалоге выяснить то, что для обучающихся будет значимо и интересно, сможет их замотивировать.

Симуляционная бизнес-игра эффективна тогда, когда в процессе ее проведения сочетаются различные формы работы: индивидуальная, групповая. Педагогу-модератору необходимо стремится чередовать эти формы работы. Для этого на этапе игры «изучение ситуации» студентам можно предложить выполнить задание самостоятельно, затем - в микрогруппе, далее - в студенческой группе. По такому принципу построены многие игры, применяемые нами в рамках читаемых дисциплин.

Рабочая атмосфера в аудитории также предопределяет ход игры. Открытость и доброжелательность участников, честная конкуренция во время обсуждения задает позитивный тон игры, способствует выработке многообразия решений. Педагогу важно создавать и поддерживать такую атмосферу в аудитории, когда участники не только бы получали знания, но и удовлетворение от причастности к игре.

Любая учебная группа представляет собой совокупность микрогрупп, в которые студенты самостоятельно объединяются на основе общих целей, интересов. Таких 
неформальных групп в формальной студенческой группе может быть много. Все зависит от размера последней. Чем больше обучающихся в учебной группе, тем больше и неформальных микрогрупп в ней. Преподавателю необходимо установить контакт с неформальными группами, активизировать деятельность их лидеров, чтобы те оказали влияние на студентов группы и побудили их к участию в игре.

Определенная группа требований предъявляется к участнику игры, т.е. к студенту. При проведении игры должны быть созданы условия, позволяющие направить обучающихся на творческую самостоятельную проработку материала. Информация, которую необходимо найти, изучить, проанализировать студенту в рамках самостоятельной работы (КСР), должна быть доступна в электронной информационно-образовательной среде вуза, понятна и вызывать у него интерес.

Последняя группа требований касается организационно-технических условий проведения симуляционной деловой игры: состояние аудитории, ее техническая оснащенность (возможность мобильной перестановки мебели в учебной аудитории; наличие мультимедийного проектора и компьютера для демонстрации хода и результатов игры в Power Point; персональные мобильные ПК с программным обеспечением (ноотбуки, нетбуки); доступ к сети Интернет); подборка раздаточного и демонстрационного материала, бланков для оценивания хода игры, ее участников, работы групп; определение временных границ на выполнение тех или иных этапов игры; распределение ролей студентов в игре, назначение экспертов и др.

Игнорирование тех или иных требований значительно понижает качество проведения игры, ее ценность при изучении темы дисциплины.

Игра - сложный динамический процесс, состоящий из определенных этапов $[1 ; 3 ; 4]$.

Этап «введение в игру» помогает участникам понять цель, основные правила ее проведения. Если не проговорить последние, то можно получить разночтение и неправильное толкование ситуации для разбора во время групповых и коллективных дискуссий.

На втором этапе необходимо разделить учебную группу на подгруппы. Оптимальный размер подгруппы четыре - пять человек. Если в группе двое и они находятся в дружеских отношениях, то на этапе обсуждений возможен выбор варианта решения более авторитетного участника без дискуссии. Слишком большое количество членов в микрогруппе - шесть, семь - приведет к тому, что мнения отдельных студентов могут не учитываться на этапе полемики, или, напротив, растянет процесс об- суждения из-за невозможности выработать групповое решение, принимаемое большинством. При организации микрогрупп важно учесть особенности взаимодействия в студенческой аудитории. Ее участники должны быть психологически совместимы, но при этом разносторонними по взглядам. Последнее необходимо для выработки различных путей решения проблемы.

Третий этап - индивидуальное изучение проблемной ситуации. Исходная информация может быть дана как на занятии, так и заранее. Лучше если участники игры будут владеть информацией заранее, поскольку не затрачивается время на ее ознакомление на учебном занятии. В настоящее время это не вызывает сложностей. Каждая студенческая группа на первом году обучения в вузе создает свой электронный почтовый адрес, на который преподаватели высылают задания, необходимую информацию в течение четырех лет обучения. Активная переписка со студентами по учебным вопросам ведется посредством социальных сетей.

После изучения ситуации начинается активный процесс игры, заключающийся в выработке коллективных вариантов решений и формирования результата. Этот этап самый сложный, зачастую сопряженный с конфликтами, очень часто скрытыми или косвенными. В связи с этим педагогу-модератору необходимо направлять усилия участников групп на достижение результата, не отстраняться и не уходить в сторону при возникновении активных дискуссий и предконфликтных ситуаций, применять психолого-педагогические методы предотвращения и разрешения конфликта, направлять и координировать деятельность обучающихся по ходу игры, подчеркивать важность многообразия решений.

На этапе подведения итогов дается оценка принятых решений, подсчитываются баллы, сумма отклонений между индивидуальным и коллективным, а также групповым и общим решениями.

Анализ деятельности групп, оценка работы ее участников - следующие этапы игры. Для того чтобы такая оценка состоялась, рекомендуется вести протоколы во время игры. Информация, характеризующая активность группы, ее членов может заносится в протоколы как самим преподавателем, так и назначенными им студентами, выступающими в роли экспертов. Как правило, экспертами назначаются студенты, вышедшие с больничного, и в связи с этим не имеющие теоретической базы для прохождения игры. Экспертами могут быть и специально подготовленными студенты. Назначение экспертов зависит от конкретных обстоятельств игры. Типичный протокол для индивидуального оценивая студента в работе в группе представлен на рисунке 1.

Далее следует этап игры, где обсуждаются оптималь- 
ные решения, выносится единое, правильное, обоснованное, наиболее приближенное к реальным обстоятельствам и др.

\begin{tabular}{|l|l|l|l|l|l|}
\hline Имя & Слушает & $\begin{array}{l}\text { Задает } \\
\text { вопросы }\end{array}$ & $\begin{array}{l}\text { Высказывает } \\
\text { мнение }\end{array}$ & $\begin{array}{l}\text { Дает идеи, } \\
\text { информацию }\end{array}$ & $\begin{array}{l}\text { Выражает } \\
\text { несогласие, } \\
\text { критикует }\end{array}$ \\
\hline & & & & & \\
\hline
\end{tabular}

Рис 1. Оценка участия членов группы в обсуждениях игры

На этапе - «общая дискуссия» - подводятся итоги встречи. Вопросами для оценки игры могут быть: Интересна ли игра? Что можно было сделать иначе, если бы Вы играли еще раз? Какими могли быть другие результаты игры? В силу каких причин? Ориентирована ли игра на имеющиеся у участников знания? Были ли учебные материалы, рекомендованные к подготовке игры, полезны, доступны? Какова эффективность игры? Что Вы можете предложить для совершенствования игры? и проч. Если возникает ограничение во времени для осуществления завершающего этапа игровой ситуации, то можно провести анкетирование участников. Результаты опроса обрабатываются, систематизируются преподавателем, выявляются слабые игровые стороны, которые в дальнейшем корректируются.

Важно не игнорировать такие этапы игры, как дискуссия, индивидуальная оценка участника и групп в целом. На основе рекомендаций студентов, обсуждения итогов в дальнейшем можно скорректировать ход игры, поработать с текстом, протоколами оценивания и многое др.

Значение и роль симуляционных деловых игр в учебном процессе обусловлена их положительными свойствами. В числе них то, что они позволяют:

- углубленно, всесторонне изучить управленческую проблему путем разработки всевозможных групповых решений в условиях значительного сокращения времени, отводимого на проведение учебного занятия;

- научиться работать с информацией, когда развиваются аналитические способности. Обучающиеся формируют умения, навыки находить нужный материал, отсекая лишнее, анализировать, соотносить, синтезировать его;

- устанавливать причинно-следственные связи при выявлении проблемы управления, выработке решений, обосновании их целесообразности и эффективности;

- помимо теоретического мышления в ходе игры формируются профессиональные навыки выполнения должностных обязанностей, при повторяющихся ситуациях они могут быть доведены до автоматизма;
- формируется и личный опыт принятия решений. Игра полезна тем, что ошибки, совершенные ее участниками, осмысливаются и это дает возможность их избежать в будущем - в профессиональной деятельности;

- игра непросто обучает студентов, но развивает их. Прорабатывая конспект лекции, представленный преподавателем раздаточный и демонстрационный материал, участник игры обращается к дополнительной литературе для поиска новых идей и решений;

- в ходе игры обучающиеся получают навыки коммуникативного общения, происходит процесс социализации отдельно взятого студента в группе. Игра учит непросто слушать позицию другого, а слышать и принимать ее, особенно если та верна $[1 ; 3 ; 4]$.

Помимо весомых преимуществ симуляционных деловых игр, у них есть и недостатки. Игровая форма расслабляет отдельных студентов, так как оценка их работы на практическом занятии может базироваться на результатах микрогруппы. Это приводит к пренебрежительному отношению к самостоятельной проработке теоретического материала или пассивному поведению при обсуждениях, соглашательской позиции при выработке коллективного решения.

Отсутствие качественной, доступной цифровой платформы, позволяющей преподавателю самостоятельно формировать цели и условия симуляционной деловой игры, не всегда позволяет дать более объективную оценку проблемы и принимаемых решений; сравнить ожидаемый результат с реальной действительностью.

Трудности при организации симуляционной игры возникают при установлении критериев и этапов ее проведения. Зачастую игнорируется обратная связь при оценивании игры, когда не учитываются пожелания и рекомендации студентов для ее корректировки; из-за ограниченности во времени проводится поверхностный анализ результатов работы студентов.

Для того, чтобы провести полуторачасовую симуляционную деловую игру, педагог вынужден потратить куда больше времени на ее подготовку: установить контакт с аудиторией; выявить их интересы, особенности коммуникации и взаимодействия в учебной группе; заручиться поддержкой неформальных лидеров. Очень много времени отводится на проработку самого материала для игры; подготовку демонстрационного и раздаточного материала, доведения его до обучающихся; согласования с диспетчерской по выбору аудитории, оснащенной необходимой техникой для проведения игры и т.д. Все это приводит к тому, что ряд преподавателей уделяют предпочтения решению задач, разбору практи- 
ческих ситуаций и case-study.

Однако имеющие недостатки при организации, проведении и оценки игры не умоляют ее ценности и значимости. На сегодняшний день деловые игры остаются одной их важной образовательной технологией обучения студентов, отраженной в рабочей программе учебной дисциплины. Симуляционные деловые игры способны оказать практическую помощь не только в процессе обучения студентов, персонала компании, но и содействовать успешному внедрению профессиональных стандартов на предприятиях. Особенность симуляционной деловой игры состоит в том, что все участники обяза- тельно проходят этап погружения в смоделированную ситуацию. Выполняя действия, аналогичные тем, которые реализуются в их профессиональной деятельности, они нарабатывают и накапливают опыт решения профессиональных и управленческих задач. Всестороннее изучение студентами вариантов решений, их экономическое обоснование, выявление приемлемых и целесообразных, отсеивание ошибочных, неэффективных, позволяет в будущем снизить вероятность их повторения в профессиональной деятельности. Самоанализ поведения и оценка других членов группы, сравнение результатов, позволяет сформировать тактику взаимодействия с окружающими в дальнейшем.

\section{ЛИТЕРАТУРА}

1. Алёшина 0.Г. Деловая игра как средство развития профессиональных компетенций студентов / О.Г. Алёшина // Молодой ученый. - 2014. - № 4 (63). C. 908 - 910. - URL: https://moluch.ru/archive/63/9313/ (дата обращения: 08.10.2020).

2. Бельчиков Я.М. Деловые игры / Я.М. Бельчиков, М.М. Бирштейн. - Рига: Авотс, 1989. - 304 с.

3. Бургат В.В. Деловая игра как метод активного обучения / В.В. Бургат // Сибирский торгово-экономический журнал. - 2014. - №1 (19). - С. 48 - 51.

4. Дюжева М.Б. Обучение бакалавров вуза на основе деловых игр / М.Б. Дюжева, Н.И. Роговская. - Сибирский торгово-экономический журнал. - 2016. № 3 (24). - C. $71-73$.

5. Панова А.Н. История развития деловой игры как одного из методов активного обучения / А.Н. Панова // Психология и педагогика: методика и проблемы практического применения. - 2010. - № 17. - С. $327-332$.

6. Рыжик Н. Деловая игра как метод активного обучения / Н. Рыжик, 0. Молотова - Кадровик. «Кадровый менеджмент (управление персоналом)». 2013. - № 2. - URL: http://hrportal.ru/article/delovaya-igra-kak-metod-aktivnogo-obucheniya (дата обращения: 08.11.2020).

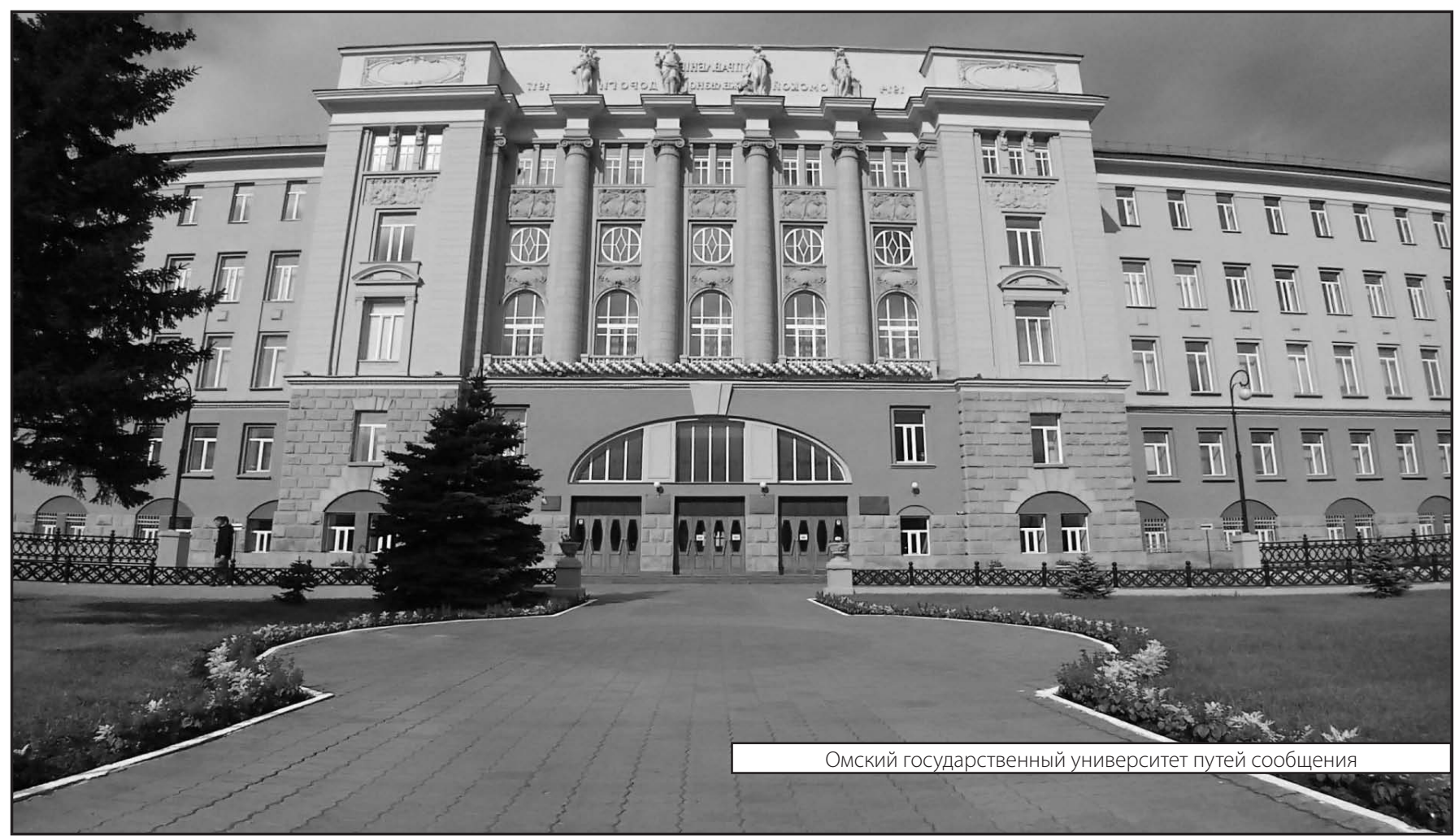

